\title{
Morphological spectrum of intracranial meningiomas on computed tomography (CT) and magnetic resonance imaging (MRI)
}

\author{
Rishi Philip Mathew ${ }^{1, *}$, Kumar Muthukumar², Praveen Kumar Natesan ${ }^{3}$, Muthukalathi Karunakaran ${ }^{4}$ \\ ${ }^{1}$ Consultant, ${ }^{2,3,4}$ Senior Consultant, Dept. of Radio-Diagnosis, K.G. Hospital and Postgraduate Medical Institute, Coimbatore, \\ Tamil Nadu, India
}

*Corresponding Author:

Email: dr_rishimathew@yahoo.com

\begin{abstract}
Meningiomas are the most common extra axial and non-glial primary neoplasms of the central nervous system. They account for nearly $15 \%$ of all intracranial neoplasms. The present study was planned to identify and describe the morphological and imaging characteristics of both typical and atypical meningiomas on CT and MRI, including Diffusion Weighted Imaging (DWI) and MR Spectroscopy (MRS). CT and MRI images of 43 patients histologically proven to have meningioma were retrospectively evaluated. The images were evaluated for- tumor location, imaging characteristics, atypical patterns of presentation and as well as advanced imaging features. Statistical analysis used included percentage and frequency. Institutional ethical committee clearance was obtained prior to commencement of the study. Our study population comprised of 23 females and 20 males. The bulk of our population belonged to $5^{\text {th }}$ decade group (44\%). The most common tumor site was the frontal lobe (40\%). Features seen on imaging included- well defined margins $(100 \%)$, broad dural base $(67 \%)$, calcification-84\% $(\mathrm{n}=36 / 43)$ and peritumoral edema (51\%). On MRI, $84 \%$ and $67 \%$ of the lesions were T1 isointense and T2 mildly hyperintense respectively, when compared to the brain parenchyma, diffusion restriction was variable (benign meningiomas- $46 \%$ and atypical meningiomas-100\%). Choline $(100 \%)$ and Alanine peaks $(28 \%)$ were observed on MRS. On post contrast imaging, homogeneous enhancement was seen in $95 \%$, while a dural tail was seen in only $51 \%$ of the cases. Benign meningiomas present with typical extra-axial features (broad dural base, white matter buckling, CSF cleft, dural tail etc.), while atypical meningiomas have varied presentations which include-cystic/necrotic areas, significant vasogenic edema with mass effect and diffusion restriction on DWI.
\end{abstract}

Keywords: Meningioma, Extra-axial lesion, Dural tail.

\section{Introduction}

Meningiomas are the most common extra axial and non-glial primary neoplasms of the central nervous system. They account for nearly $15 \%$ of all intracranial neoplasms. The majority of meningiomas are benign and up to $10 \%$ are atypical or malignant, characterised histologically by necrosis, nuclear disorganization, prominent nucleoli and increased mitosis ${ }^{1}$. Meningiomas are more commonly seen in the middle and late decades of life with a strong female predilection $(2: 1){ }^{2}$ Early detection of meningiomas with accurate diagnosis has considerably improved over the years with advancement of Multi-Detector Computed Tomography (MDCT) and Magnetic Resonance Imaging (MRI) technology. These crosssectional imaging modalities not only provide useful information regarding the meningioma structure and composition but also inputs regarding their functional aspect. Once a meningiomas has been detected imaging plays a crucial role in pre-operative planning and postoperative evaluation. ${ }^{3}$

\section{Materials and Methods}

Images (CT and MRI) of 43 patients with histologically proven intracranial meningiomas were retrospectively evaluated from our hospital database from 2010 to 2016 following approval from our institutional ethics committee board. CT scan was carried out by a 128 slice MDCT Siemens (SOMATOM AS+) scanner with standard CT protocol for head and neck. Non-ionic iodinated contrast material was administered in all patients to evaluate the lesion enhancement pattern and characteristics. MR imaging was carried out on a 1.5 Tesla Scanner (Siemens Magnetom AVANTO, Erlangen, Germany) by a using a dedicated head coil. The imaging protocol used were-axial and sagittal T1 weighted (W) spinecho (SE) (TR/TE: 500/50 ms), axial and coronal T2W turbo SE (TR/TE: 4000/90 ms), axial and coronal postcontrastT1WSE (TR/TE:500/50 ms) imaging after intravenous contrast injection (gadopentetate dimeglumine_0.1 mmol $/ \mathrm{kg}$ ), with a $5 \mathrm{~mm}$ thickness and $10 \%$ interslice gap. All studies also included a single shot echo planar DW imaging (applied three $b$ values with a maximum of $1000 \mathrm{~s} / \mathrm{mm} 2$ and a TR/TE of $3500 / 94 \mathrm{~ms}$; matrix of $256-512,5 \mathrm{~mm}$ slice thickness) in the axial plane. ADC maps were automatically generated on site and transferred to the Picture Archiving and Communication Systems (PACS).The conventional images were evaluated for- the tumor site, presence/absence of edema, presence/absence of extraaxial signs (eg. CSF cleft, displaced and expanded subarachnoid vessels, gray-white matter buckling, broad dural base and bony hyperostosis), presence of signal voids on $\mathrm{T} 1$ and $\mathrm{T} 2$ (calcification/ vessels/ fibrosis), presence of haemorrhage, heterogeneity, presence of necrosis/cystic areas, presence of calcification, margins (well defined or ill-defined) and bone changes. ADC values were calculated by using a software available on the workstation provided by the 
manufacturer. To minimize variability, intratumoral ADC values were obtained by placing manually the region of interest (ROIs) in the solid part of the tumor, excluding cystic or calcific areas. For large lesions, mean values of 3 ROIs were obtained. Control ADC values were recorded by placing ROIs in the normal white matter of brain parenchyma on the contralateral side unaffected by the tumor. The ADC ratio was calculated using the formulae: $\mathrm{ADC}$ ratio $=\mathrm{ADC}$ of the tumor $\div$ ADC of normal white matter.

Single voxel point resolved MR spectroscopy (MRS) was performed after conventional MR imaging examination using a standard head coil in all cases. A volume of interest of 1.0 to $8.0 \mathrm{~mL}$ was selected from the centre of the lesion with edges of the voxel well within the solid tumoral portion, avoiding cystic or necrotic areas when present, and with minimum contamination from the surrounding non-tumoral tissue. Four proton MR spectra were acquired from the same volume of interest for every case: 1) water-suppressed spin-echo short TE (2000/30/ 92-184) (TR/TE/averages); 2) water-suppressed spin-echo long TE $(2000 / 136 / 126-252)$; 3) unsuppressed water spinecho long TE (2000/136/16); and 4) unsuppressed water spin-echo short TE (2000/30/16). A total of 512 data points was collected over a spectral width of 1000 Hz. Spectrum analysis was performed off-line with the available software. Assignment of resonances of interest included- lipids(LIP09) at $0.90 \mathrm{ppm}$, lipids (LIP13) at $1.30 \mathrm{ppm}$, lactate (LACT) as a doublet centred at $1.35 \mathrm{ppm}$, alanine (Ala) as a doublet centred at $1.47 \mathrm{ppm}, N$-acetylaspartate and other $N$-acetylcontaining compounds (NACC) at $2.02 \mathrm{ppm}$, glutamate and glutamine (GLX) at $2.35 \mathrm{ppm}$, creatine plus phosphocreatine (CR) at $3.03 \mathrm{ppm}$, choline and other trimethylamine- containing compounds (CHO) at 3.20 $\mathrm{ppm}$, and glycine or myo-inositol (Gly/MI) at 3.55 $\mathrm{ppm}$. The assignment of resonances was based on previous documented studies of brain tumors and phantom studies.

Statistical analysis included percentage frequency.

\section{Results}

Females formed the bulk of our patients $(53 \%$, i.e. $n=23 / 43$ ). Majority of the patients belonged to the $5^{\text {th }}$ decade age group (44\%), followed by the $6^{\text {th }}$ decade (23\%) (Fig. 1).

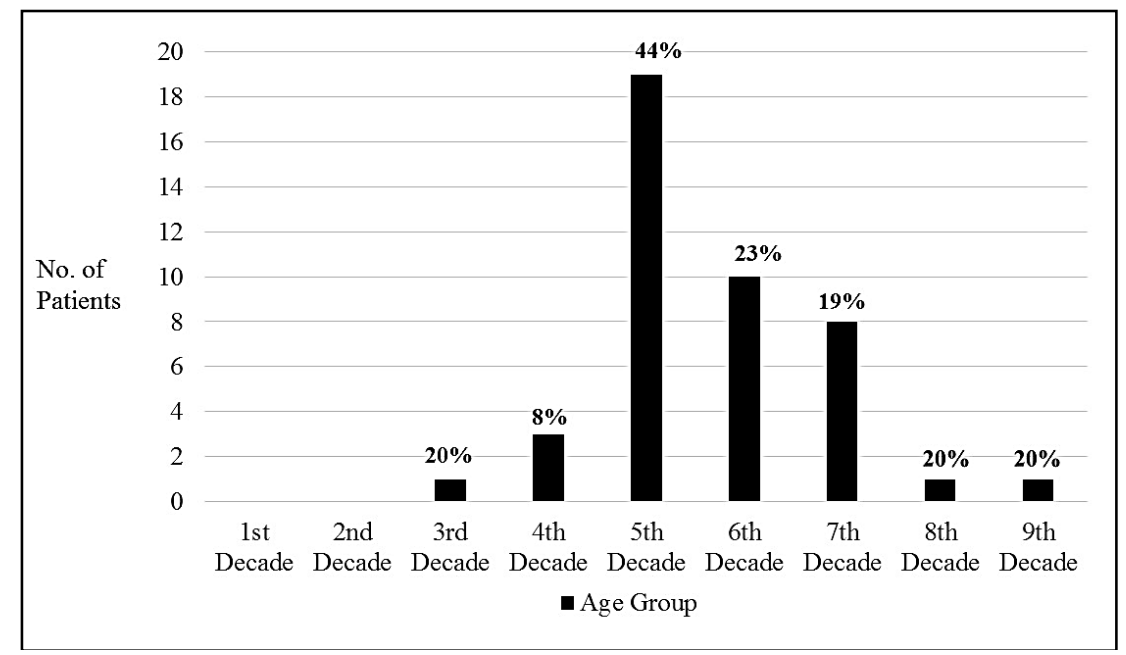

\section{Fig. 1: Age distribution of study population}

With regards to the tumour site (Fig. 2), majority of the meningiomas in our study were located in the frontal lobe $(n=17 / 43$ i.e. $40 \%)$, parietal lobe $(n=14 / 43$ i.e. $33 \%)$, temporal lobe $(n=8 / 43$ i.e. $19 \%)$. All the lesions in our study population presented with well- defined margins. Solid density was observed in $95 \%$ of the lesions, with cystic/ necrotic areas noted in only 2 cases. Calcification was observed in $84 \%$ of the cases $(n=36 / 43)$, of which two cases (one benign and one atypical) showed intense or hyper-calcification (Fig. 3). 

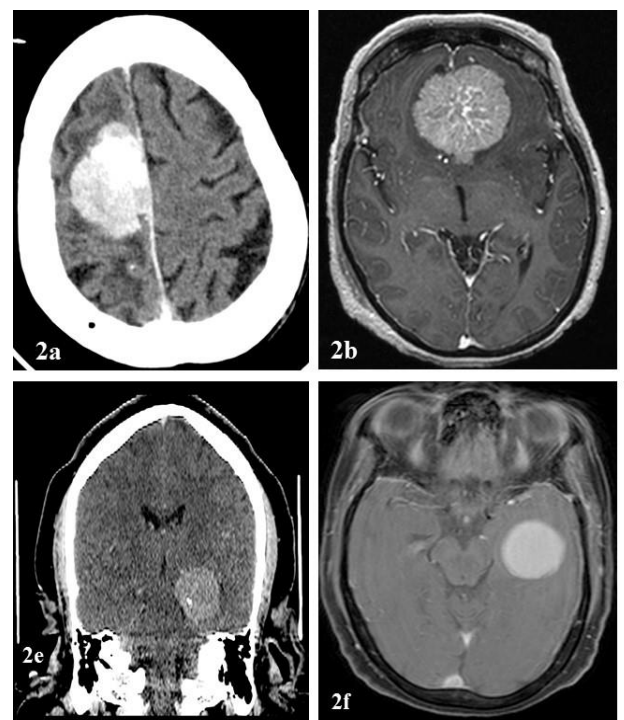
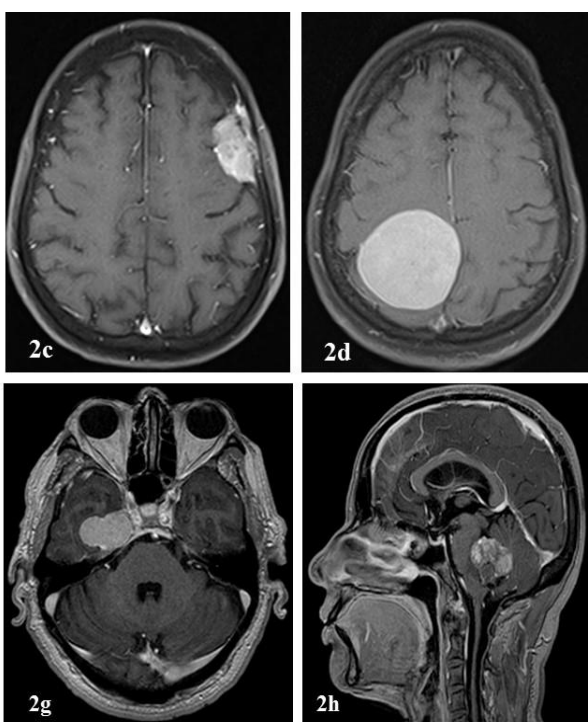

Fig. 2: Meningiomas and their various sites seen in our study population- parasagittal (2a), olfactory groove (2b), left frontal lobe (2c), right parietal lobe (2d), left tentorial (2e), left temporal lobe, (2f), Meckel's cave $(2 \mathrm{~g}), 4^{\text {th }}$ ventricle $(2 \mathrm{~h})$
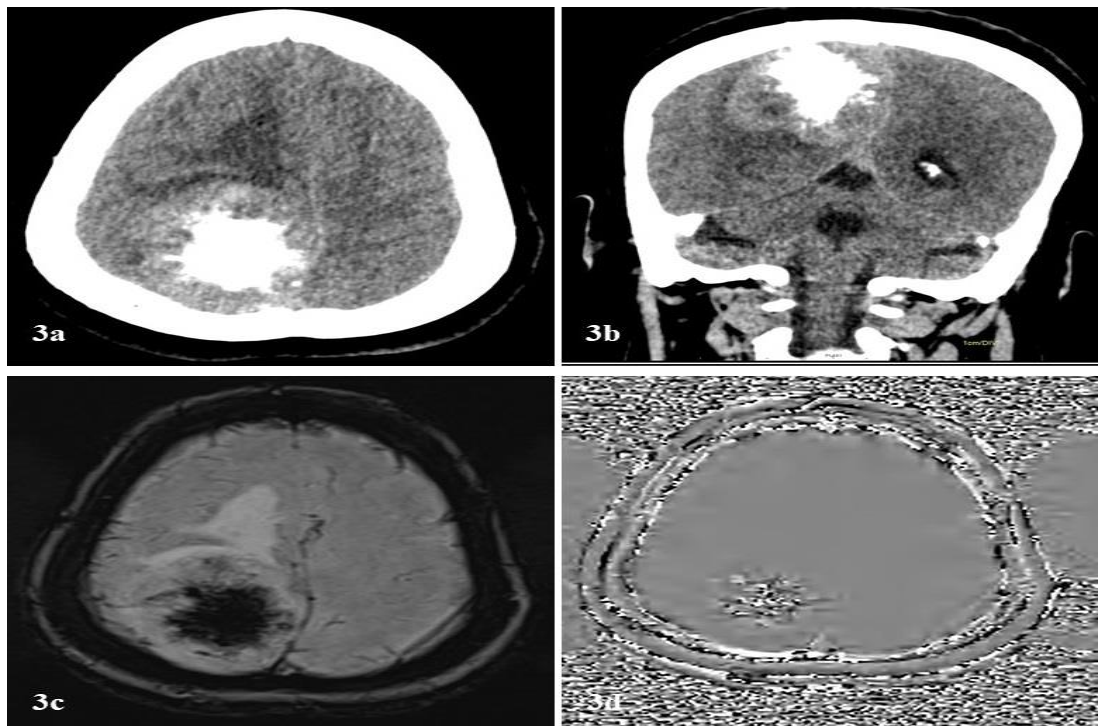

Fig. 3: CT axial (3a), coronal (3b) and MR SWI (3c) and GRE source (3d) images showing a right parietal lobe meningioma (WHO grade 1) with hyper-calcification in a 62 year old female patient

All of the lesions (95\%) except for two showed homogeneous enhancement after contrast administration. $80 \%$ of the cases showed intense homogeneous enhancement. On plain CT, all of the cases except for one were hyperdense compared to brain parenchyma. The one case where the lesion was isodense to brain parenchyma was located in the left temporal lobe, obliterating the left sylvian fissure and adjacent gyri raising the suspicion of a possible mass, which was confirmed following intravenous contrast administration. On T1-WI, $84 \%$ of the cases $(n=36 / 43)$ were isointense to the adjacent grey matter, while the other cases were hypointense. On T2-WI, 67\% ( $\mathrm{n}=$ 29/43) of the cases were mildly hyperintense when compared to adjacent grey matter, while the remaining cases were isointense. Extra-axial features that were observed in our study included- a broad dural base$67 \%(n=29 / 43)$, white matter buckling-74\% $(n=32 / 43)$, a CSF cleft- $56 \%(\mathrm{n}=24 / 10)$ and a dural tail-51\% $(n=22 / 43)$. Adjacent subarachnoid vessels were displaced in $35 \%(n=15 / 43)$ of the cases. Peritumoral edema was noted in $50 \%$ of the cases, of which two cases $(5 \%)$ presented with severe vasogenic edema and mass effect. On DWI, 41 of the benign meningiomas had variable single intensity, hypointense $(n=7)$, isointense $(n=15)$ and hyperintense $(n=19)$. Two atypical cases of meningiomas showed hyperintensity on DWI. The mean ADC values were- 0.96 $\pm 0.4 \times 10^{-3} \mathrm{~mm}^{2} / \mathrm{s}$ for benign meningiomas and 0.82 $\pm 0.1 \times 10^{-3} \mathrm{~mm}^{2} / \mathrm{s}$ for atypical meningiomas. On MRS, a 
Choline peak $(100 \%)$ was noted in all of the cases, while a discernible Alanine peak was observed in $28 \%$ $(n=12 / 43)$ of the cases. Two cases which had atypical imaging features- cystic/necrotic areas, heterogenous enhancement and extensive vasogenic edema with mass effect in the form of midline shift, were histologically proven to be atypical (Grade 2) meningiomas (Fig. 4).
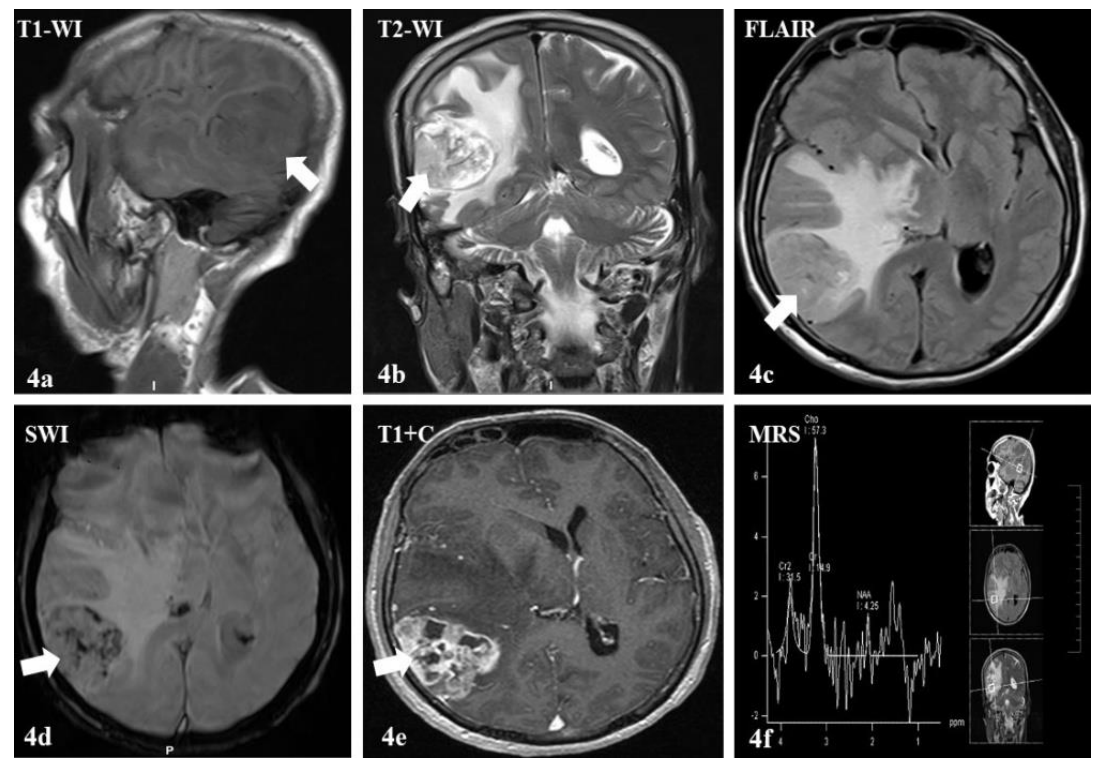

Fig. 4: A right temporallobe atypical meningioma (WHO grade 2) in a 65-year-old male patient, showing cystic/necrotic areas, with heterogenous enhancement, significant mass effect and strong peritumoral edema

A summary of the morphological features of intracranial meningiomas seen in our study group has been summarized in Table 1.

Table 1: Summary of the morphological features of meningioma in our study group

\begin{tabular}{|c|c|}
\hline Males vs Females & $-47 \%(n=20 / 43)$ vs. $53 \%(n=23 / 43)$ \\
\hline Commonest age group & $-5^{\text {th }}$ decade $(44 \%)$ \\
\hline Commonest tumor location & - $\quad$ Frontal lobe $=17 / 43(40 \%)$ \\
\hline Tumor margin & - $\quad$ Well defined $(100 \%)$ \\
\hline Tumor density & $\begin{array}{ll}- & \text { Solid density }=41 / 43(95 \%) \\
\text { - } & \text { Solid-Cystic density }=2 / 43(5 \%)\end{array}$ \\
\hline Calcification & $\begin{array}{ll}- & n=36 / 43(84 \%) \\
- & \text { Hyper-calcification }=2 \text { cases }\end{array}$ \\
\hline Enhancement pattern & $\begin{array}{ll}- & \text { Homogenous }=41 / 43(95 \%) \\
- & \text { Heterogenous }=2 / 43(5 \%)\end{array}$ \\
\hline Extra axial features & $\begin{array}{ll}\text { - } & \text { White matter buckling: } \mathrm{n}=32(74 \%) \\
\text { - } & \text { Signal void pseudocapsule: } \mathrm{n}=5(12 \%) \\
\text { - } & \text { CSF cleft: } \mathrm{n}=24(56 \%) \\
\text { - } & \text { Dural tail: } \mathrm{n}=10(23 \%) \\
\text { - } & \text { Subarachnoid vessel displacement: } \mathrm{n}=15(35 \%) \\
\text { - } & \text { Broad dural base: } \mathrm{n}=38(88 \%)\end{array}$ \\
\hline Peritumoral edema & $-\mathrm{n}=22 / 43(51 \%)$ \\
\hline WHO grade of Meningioma & $\begin{array}{l}\text { - } \quad \text { Grade I (benign meningioma) }=95 \% \\
\text { - } \quad \text { Grade II (atypical meningioma) }=5 \% \\
\text { - } \quad \text { Grade III (anaplastic meningioma) }=0\end{array}$ \\
\hline \multicolumn{2}{|c|}{$\begin{array}{ll}\text { Imaging features of atypical meningiomas }(\mathrm{n}=2) \text { in our study group } \\
- & \text { Cystic/necrotic areas: } \mathrm{n}=2 / 2(100 \%) \\
- & \text { Ring enhancement: } \mathrm{n}=1 / 2(50 \%) \\
- & \text { Hyper-calcification: } \mathrm{n}=1 / 2(50 \%) \\
- & \text { Severe peritumoral edema with midline shift: } \mathrm{n}=2 / 2(100 \%) \\
- & \text { Intraventricular location: } \mathrm{n}=1 / 2(50 \%)\end{array}$} \\
\hline
\end{tabular}




\section{Discussion}

Meningiomas are the most common non-glial primary intracranial tumors. These extra-axial neoplasms arise from arachnoid cap cells located along the dural venous sinuses, however they may also arise from meningothelial cells located in spinal or ectopic locations. ${ }^{4}$ Although they may be seen in any region of the central nervous system (CNS), the majority are commonly seen over the cerebral convexities or at the cranial base. The overall incidence of meningiomas in the general population is roughly about $2.3 / 100,000$ people. ${ }^{5}$ The incidence of intracranial meningiomas increases with every decade and peaks in the $7^{\text {th }}$ decade in men $\left(6 / 100,000\right.$ people) and in the $8^{\text {th }}$ decade among women (9.5/100,000 people). ${ }^{5,6}$ Meningiomas are rare in young adults and children, they have an incidence of about of 1-3\% of all intracranial tumors in people aged up to 20 years and $13.5 \%$ up to the age of 20-34 years, which is considerably lower than the incidence seen in patients greater than 40 years of age. Meningiomas are more common among males in patients aged less than 20 years while they have a female predominance among patients aged more than 20.,7 Meningiomas are graded into 3 subtypes (Grade I, II and III) based on the World Health Organization (WHO) classification. Approximately $78 \%$ of all meningiomas are benign (WHO Grade I), $20.4 \%$ are WHO grade II or atypical with a high tendency to recur and $1.6 \%$ are WHO grade III or anaplastic. ${ }^{8}$ Benign meningiomas (Fig. 5) have been further subclassified based on their histopathological features as-meningothelial, fibrous (fibroblastic), transitional (mixed), psammomatous, angiomatous, microcystic, secretory, lymphoplasmacyte-rich and metaplastic. ${ }^{9}$

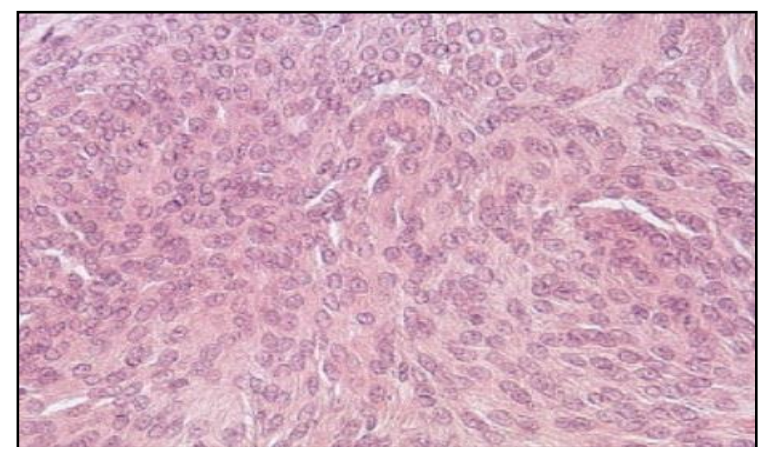

Fig. 5: Histology showing a benign meningioma with psammoma bodies

A rare entity called benign metastasizing meningioma has also been reported..$^{10} \mathrm{~A}$ high percentage of meningiomas in patients under the age of 20 years have been reported to be histologically atypical or anaplastic, displaying an aggressive pattern of growth and recurrence. The most common intracranial site for meningiomas include- cerebral convexities (20-34\%), parasagittal location (18-22\%) and the sphenoid ridge (17-25\%). Cerebellopontine angle (CPA) is another common site for meningiomas, and these tumors account for nearly $10-15 \%$ of all CPA tumours. ${ }^{4,11}$ Intraventricular meningiomas account for only $0.5-3 \%,{ }^{12}$ while extracranial meningiomas are extremely rare, accounting for less than $2 \%$ of all meningiomas, of which nearly $68 \%$ have calvarial involvement. Intraosseous meningiomas have rarely been reported in the frontoparietal and orbital regions. ${ }^{13}$ The exact etiology of meningiomas have not been understood. However, they have been known to be associated with Neurofibromatosis type 2, radiation and trauma. ${ }^{14}$ Other genetic conditions that may predispose to meningiomas include- Meningioangiomatosis (MA), Gorlin syndrome and Down's syndrome. ${ }^{15}$ Plain radiography has been superseded by advanced modalities such as MDCT and MRI. In majority of the patients, plain radiographs are normal. Findings when present include- hyperostosis, calcification, and osteolysis associated with the tumours. ${ }^{16}$ On plain MDCT, meningiomas appear as lobulated, homogenous hyperdense masses when compared to the brain parenchyma. Following contrast administration, these tumours usually show intense and homogenous enhancement. Calcification is seen in $20-27 \%$ of all cases and is usually punctated, but can be large, conglomerate, peripheral or central. Additional features include hyperostosis (18-50\%) of the adjacent calvarial bone or skull base and rarely bone destruction may be seen in approximately $3 \%$ of the cases. ${ }^{17}$ On noncontrast MRI, meningiomas appear as well defined, lobular, extra axial masses with inward displacement of cortical gray matter. The tumors appear hypo- to isointense on T1 weighted images (T1-WI) and iso- to hyper-intense on T2 weighted images (T2-WI). On post contrast images following administration of gadolinium, the masses show early homogenous enhancement persisting late into the venous phase, also known as the 'mother in law' phenomenon. ${ }^{3,18}$ The 'dural tail' sign, although is seen in approximately $60 \%$ of all cases of meningioma on post contrast CT and MR images. It refers to the linear dural enhancement seen adjacent to the lesion. The 'dural tail' sign is not specific for meningioma and may be seen with other tumours such as- chloroma, lymphoma, sarcoidosis, vestibular schwannoma, metastases, syphilitic gumma and aggressive papillary middle ear tumor. ${ }^{19,20}$ Goldsher et al in 1990 adopted criteria to establish the presence of a dural tail on imaging. These were- (a) The tail should be seen on two successive imaging sections through the tumor, (b) the tail should taper smoothly away from the tumor, and (c) the tail must enhance more than that of the tumour itself. ${ }^{21}$ Other additional findings which may be seen on MRI include perilesional edema and hyperostosis. Imaging findings confirming the extra-axial location of the lesion include- presence of a CSF cleft, pseudocapsule and gray-white matter buckling of underlying brain parenchyma. ${ }^{22}$ Diffusion weighted Imaging may be 
useful to differentiate grade I meningiomas from grade II/IIII meningiomas. Nagar $\mathrm{VA}$ and et $\mathrm{al}^{23}$ retrospectively compared conventional and DW MR images (b-value $1000 \mathrm{~s} / \mathrm{mm}^{2}$ ) between 25 atypical/malignant and 23 benign meningiomas and found that the mean $\mathrm{ADC}$ of atypical/malignant meningiomas $\left(0.66 \pm 0.13 \times 10^{-3} \mathrm{~mm}^{2} / \mathrm{s}\right)$ were significantly lower when compared to benign meningiomas $\left(0.88 \pm 0.08 \times 10^{-3} \mathrm{~mm}^{2} / \mathrm{s}\right)$. In addition to this, the mean NADC (normalized ADC) ratio in the atypical/malignant group $(0.91 \pm 0.18)$ were also significantly lower than the benign group $(1.28 \pm 0.11)$, without overlap between groups. Surov $\mathrm{A}$ and et $\mathrm{al}^{24}$ conducted a similar study in 2015 and found that the mean $\mathrm{ADC}_{\text {mean }}$ value were higher in grade I meningiomas in comparison to grade II/III tumors $(0.96$ vs $0.80 \times 10^{-3} \mathrm{~mm}^{2} \mathrm{~s}^{-1}$ and grade II/III meningiomas showed lower NADC values when compared to grade I tumors (1.05 vs 1.26 ). It was also noted that a decrease in ADC and NADC on follow-up imaging could suggest dedifferentiation to a higher tumor grade. Magnetic Resonance Spectroscopy (MRS) of typical and atypical meningiomas show characteristic prominent Choline peak, absent or reduced amount of N-Acetyl Aspartate (NAA) and Creatinine (Cr) and presence of Alanine (Ala) peaks. MRS cannot reliably differentiate typical from atypical meningiomas. ${ }^{25}$ Patients with atypical meningioma (WHO grade II) may show a lactate peak on MRS26. Kousi and et $\mathrm{al}^{27}$ in their MR spectroscopic data analysis of 50 intracranial lesions (comprising 17 meningiomas, 24 high grade gliomas and 9 metastases) using 3 Tesla
(3T) MRI, noted meningiomas to have a distinct signal at $3.8 \mathrm{ppm}$, enabling the differentiation of meningiomas from other cerebral lesions. They also noted that when long TE was performed meningiomas had the highest mean $\mathrm{Cho} / \mathrm{Cr}$ ratio and the highest $\mathrm{Cho} / \mathrm{NAA}$ ratio among all intracranial tumours. The various metrics of Diffusion Tensor Imaging (DTI) may be useful in differentiating the subtypes of meningioma. Jolapara and et $\mathrm{al}^{28}$ retrospectively evaluated the various DTI metrics (tumor mean diffusivity (Dav), fractional anisotropy (FA), linear anisotropy (CL), planar anisotropy (CP), spherical anisotropy (CS) and eigen values $(\mathrm{e} 1, \mathrm{e} 2, \mathrm{e} 3))$ in 21 patients with meningioma (benign-16 and atypical-5). They noted that among the various DTI metrics both atypical and fibroblastic meningiomas showed statistically significant higher $\mathrm{CP}$ values and lower e3 values when compared with transitional meningiomas. Toh et $\mathrm{al}^{29}$ in their evaluation of 24 cases of meningioma (12 classic and 12 atypical) with DTI noted that classic meningiomas significantly had lower fractional anisotropy (FA) when compared to atypical meningiomas, and concluded that the intratumoral microscopic water motion is less organized in classic than in atypical meningiomas. Single Photon Emission Computed Tomography (SPECT) and Positron Emission Tomography (PET) may be useful to provide information regarding the various cellular processes and characteristics of meningiomas. Numerous radiopharmaceuticals used in SPECT and PET are available for imaging of meningiomas, each having their own advantage and disadvantages (Table 2). ${ }^{30}$

Table 2: A summary of the SPECT and PET radiopharmaceuticals used in the evaluation of meningiomas

\begin{tabular}{|l|c|c|c|}
\hline Tracer & $\begin{array}{c}\text { Imaging } \\
\text { Modality }\end{array}$ & Advantages & Disadvantages \\
\hline Thallium-201 & SPECT & $\begin{array}{c}\text { Information of tumor biological } \\
\text { characteristics }\end{array}$ & $\begin{array}{c}\text { Limited imaging properties, serial } \\
\text { brain SPECT studies }\end{array}$ \\
\hline $\begin{array}{l}{ }^{99 m} \text { Tc-labelled } \\
\text { compounds }\end{array}$ & SPECT & $\begin{array}{c}\text { Viability marker, prediction of } \\
\text { anticancer drug resistance related } \\
\text { to Pgp }\end{array}$ & $\begin{array}{c}\text { Small series of patients, the } \\
\text { correlation between tracer uptake and } \\
\text { tumor grading or other biological } \\
\text { characteristics, needs validation with } \\
\text { further studies }\end{array}$ \\
\hline $\begin{array}{l}{ }^{111} \text { In-Octreide and } \\
\text { Tc-depreotide }\end{array}$ & SPECT & $\begin{array}{c}\text { High sensitivity and negative } \\
\text { predictive value, differential } \\
\text { diagnosis from somatostatin } \\
\text { receptor-negative and orbital } \\
\text { tumours, differentiation between } \\
\text { postoperative scar and } \\
\text { recurrence, selection of patients } \\
\text { for somatostatin analogue-based } \\
\text { therapies }\end{array}$ & $\begin{array}{c}\text { Specificity depends on the BBB } \\
\text { integrity, difficulty in detecting small } \\
\text { tumors, limited imaging properties of } \\
\text { 111In, few studies with 99mTc- } \\
\text { depreotide }\end{array}$ \\
\hline${ }^{18} \mathrm{~F}-\mathrm{FDG}$ & PET & $\begin{array}{c}\text { Prognostic information } \\
\text { (prediction of recurrence and } \\
\text { survival) }\end{array}$ & $\begin{array}{c}\text { High uptake in normal gray matter } \\
\text { not tumor specific }\end{array}$ \\
\hline${ }^{11} \mathrm{C}$ or ${ }^{18} \mathrm{~F}$ labelled \\
amino acids & PET & $\begin{array}{c}\text { High tumor/background ratio, } \\
\text { identification of skull base } \\
\text { meningiomas, improve target } \\
\text { volume definition for RT }\end{array}$ & \begin{tabular}{c} 
Not useful for grading, Few studies \\
\hline
\end{tabular} \\
\hline
\end{tabular}

Panacea Journal of Medical Sciences, May-August, 2018;8(2):70-78 


\begin{tabular}{|c|c|c|c|}
\hline${ }^{11} \mathrm{C}$-choline & PET & Meningioma grading & Few studies \\
\hline $1-{ }^{11} \mathrm{C}$-acetate & PET & $\begin{array}{l}\text { Accurate tumor delineation, } \\
\text { guiding the stereotactic biopsy, } \\
\text { optimizing treatment planning } \\
\text { before radiosurgery }\end{array}$ & Not useful for grading, Few studies \\
\hline${ }^{13} \mathrm{~N}-\mathrm{NH}_{3}$ & PET & High tumor/background ratio & Not useful for grading, Few studies \\
\hline${ }^{68} \mathrm{Ga}-\mathrm{DOTATOC}$ & PET & $\begin{array}{l}\text { High tumor/background ratio, } \\
\text { identification of skull base and } \\
\text { en plaque meningioma and local } \\
\text { osseous invasiveness, } \\
\text { improvement of target volume } \\
\text { definition for RT, recurrent } \\
\text { disease, selection of patients for } \\
\text { hormonal treatment or the use of } \\
\text { DOTATOC labelled with } \beta \text { - } \\
\text { emitting radionuclides }\end{array}$ & Uptake in parasellar lesions \\
\hline
\end{tabular}

Lee et $\mathrm{al}^{31}$ evaluated 59 patients with intracranial meningiomas who underwent pre-operative FDG-PET and subsequent surgical resection, all of whom who underwent clinical followup for tumor recurrence. They noted that the tumor to gray matter ratio (TGR) of FDG uptake in WHO grade II/III meningiomas were significantly higher than in low grade (WHO grade I) meningiomas, which significantly correlated with the MIB-1 labelling index and mitotic count of the tumor. They concluded from their study that FDG uptake in meningioma was a significant predictive factor for tumor recurrence that significantly correlated with the proliferative potential of the tumor. The role of FDGPET for the evaluation of metastatic meningioma is limited in literature in the form of a few case reports. Ghodsian et $\mathrm{al}^{32}$ described a hypermetabolic sacral metastatic mass by FDG-PET/CT which was a Grade III malignant meningioma on histology. Meirelles et $\mathrm{al}^{33}$ noted a pulmonary meningioma that manifested as a solitary pulmonary nodule that had a very high metabolic activity on PET scan. Brennan and et $\mathrm{al}^{34}$ reported a case of metastatic pulmonary meningioma that presented in the form of two lung nodules, 22 years following the resection of an intracranial meningioma. However, they noted that the pulmonary nodes showed avid uptake of FDG in the periphery (standard uptake values (SUV) of 8.7 and 7.1), while the uptake was less centrally.

Treatment: Treatment for meningiomas includesurgery, radiation therapy, stereotactic radiosurgery, external beam radiation therapy (EBRT). Surgery can be gross total resection alone (GTRA) or subtotal resection alone (SRA). The Simpson grading system (Table 2) defined by Simpson, (35) is a predictive system for meningioma recurrence. It is based on brain MR imaging following resection, and correlated with histopathological findings at the time of surgical resection. Prognostic factors which can predict the survival of patients with meningiomas include- extent of resection, histological grade, patient's age and tumor location. $^{36}$ Radiation therapy (RT) needs to be considered following partial resection of a meningioma or after resection of an atypical or malignant meningioma. RT improved local control of the tumor. Several literatures exist substantiating RT as a beneficial adjunct to surgery following subtotal resection, as treatment for meningioma recurrence or as a primary therapy.

Stereotactic Radiosurgery (SRS): SRS is best reserved for meningiomas measuring $<3-4 \mathrm{~cm}$ in diameter, with well-defined margins and with enough distance from vital healthy tissues to allow for normal dose restrictions and as well as the adequate target dose. ${ }^{37}$ The most common adverse effects related to SRS are cranial nerve defects and peritumoral edema, while serious but rare side effects include peritumoral cyst formation, radiation necrosis, hypothalamic dysfunction and carotid artery stenosis. ${ }^{38}$

Hormonal Therapy: Studies have shown that meningioma growth may be hormone dependant (30\% of meningiomas are oestrogen receptor positive and $70 \%$ are progesterone receptor positive). ${ }^{39,40}$ In addition to this, about $60 \%$ of meningiomas show positive prolactin receptor staining. ${ }^{41}$ Hence, a hormonal therapy option for treatment has been proposed for those meningiomas which are benign and recurrent and not amenable to surgery or radiotherapy. The various drugs that have been used with limited or no success in the past include- oral progesterone agonist- megestrol acetate (Megace) ${ }^{42}$ progesterone antagonistmifepristone (RU-486) ${ }^{43}$ and an oestrogen receptor antagonist- oral tamoxifen. ${ }^{44}$

Biotherapy and Chemotherapy: Some studies have shown that drugs such as recombinant interferon- $\alpha,{ }^{45}$ hydroxyurea (an oral chemotherapeutic agent) ${ }^{46}$ and calcium channel antagonists ${ }^{47}$ inhibit growth of human meningioma cell lines cultured in vitro. However, these studies need to be analysed with caution since no large cohorts have been studied on humans.

Differential Diagnosis: Dural based lesions that can mimic meningioma include- Solitary Fibrous tumour, Hemangiopericytoma, Leiomyosarcoma, Dural metastases, lymphoma, Plasmocytoma, Rosai-Dorfman disease (Sinus Histiocytosis), Neurosarcoidosis, 
Melanocytic neoplasms, Plasma Cell Granuloma, Erdheim Chester Disease, Leukemia, and rarely Amyloid and Rheumatoid nodules. ${ }^{48}$

\section{Conclusion}

Intracranial meningiomas are usually hypo/isointense on $\mathrm{T} 1$ weighted MR images and iso/hyperintense on T2 weighted MR images. On post contrast administration, these lesions tend to show strong enhancement. The frontal and parietal lobes are most commonly affected, and associated findings includethe 'dural tail' sign, edema and hyperostosis. It is important to differentiate between benign and malignant meningiomas prior to surgery for both management planning and as well as for the prognostic evaluation. Although some identifiable features on convention MR images do exist, no specific feature has been found to reliably predict the tumour grade. Some vital features that favour malignancy include- the absence of visible calcium aggregates, tumour extending or 'mushrooming' away from the mass, nonhomogeneous enhancement and the presence of illdefined margins.

\section{References}

1. Russell DS, Rubinstein U. Pathology of tumors of the nervous system. 5th ed. Baltimore: Williams and Wilkins, 1989;449-483.

2. Claus EB, Bondy ML, Schildkraut JM, Wiemels JL, Wrensch M, Black PM. Epidemiology of intracranial meningioma. Neurosurgery. 2005;57:1088-1095.

3. Saloner D. Modern meningioma imaging techniques. $J$ Neurooncol. (2010) 99:333-340

4. Buetow MP, Buetow PC, Smirniotopoulos JG. Typical, atypical, and misleading features in meningioma.

Radiographics. 1991;11:1087-106.

5. Bondy M and Ligon BL. Epidemiology and etiology of intracranial meningiomas: a review. J Neurooncol. 1996;29:197-205.

6. Wiemels J, Wrensch M and Claus EB. Epidemiology and etiology of meningioma. J Neurooncol. 2010;99:307-14.

7. Drake JM, Hendrick EB, Becker LE, Chuang SH, Hoffman HJ and Humphreys RP. Intracranial meningiomas in children. Pediatr Neurosci. 1985;12:1349.

8. Toh CH, Castillo M, Wong AM, Wei KC, Wong HF, $\mathrm{Ng}$ $\mathrm{SH}$, et al. Differentiation between classic and atypical meningiomas with use of diffusion tensor imaging. Am J Neuroradiol. 2008;29:16305.

9. Perry LD, Scheithauer BW, Budka H, Von Diemling A. Meningiomas. In: Louis DN, Ohgaki H, Wiestler OD, et al., editors. World Health Organization classification of tumours of the central nervous system. $4^{\text {th }}$ ed. Lyon: IARC; 2007.

10. Mittal A, Layton KF, Finn SS, Snipes GJ, Opatowsky MJ. Cystic meningioma: unusual imaging appearance of a common intracranial tumor. Proc (Bayl Univ Med Cent). 2010;23:429-31.

11. Saleh EA, Taibah AK, Achilli V, Aristegui M, Mazzoni A, Sanna M. Posterior fossa meningioma: surgical strategy. Skull Base Surg. 1994;4:202-12.

12. Nakamura M, Roser F, Bundschuh O, Vorkapic P, Samii M. Intraventricular meningiomas: a review of 16 cases with reference to the literature. Surg Neurol. 2003;59:491-503.

13. Tokgoza N, Onera Y A, Kaymazb M, Ucara M, Yilmazc G, Tali TE. Primary Intraosseous Meningioma: CT and MRI Appearance. Am J Neuroradiol. 2005;26:2053-6.

14. Mittal A, Layton KF, Finn SS, Snipes GJ, Opatowsky MJ. Cystic meningioma: unusual imaging appearance of a common intracranial tumor. Proc (Bayl Univ Med Cent). 2010;23:429-31.

15. Rushing EJ, Olsen C, Mena H, Rueda ME, Lee YS, Keating RF, Packer RJ and Santi M. Central nervous system meningiomas in the first two decades of life: a clinicopathological analysis of 87 patients. J Neurosurg. 2005;103:489-95.

16. Ricci PE. Imaging of adult brain tumours. Neuroimaging Clin N Am. 1999;9:651-69.

17. Rohninger M, Sutherland GR, Louw DF, Sima AAF. Incidence and clinicopathological features of meningioma. J Neurosurg. 1989;71:665672.

18. Zimmerman RD, Fleming CA, SaintLouis LA, Lee BCP, Manning JJ, Deck MDF. Magnetic resonance imaging of meningiomas. AJNR. 1985;6:149-157.

19. Bourekas EC, Wildenhain P, Lewin JS, et al. The dural tail sign revisited. AJNR Am J Neuroradiol 1995; 16:1514-1516.

20. Tien RD, Yang PJ, Chu PK. "Dural tail sign": a specific MR sign for meningioma? J Comput Assist Tomogr. 1991;15:64-66.

21. Goldsher D, Litt AW, Pinto RS, Bannon KR, Kricheff II. Dural "tail" associated with meningiomas on Gd-DTPAenhanced MR images: characteristics, differential diagnostic value, and possible implications for treatment. Radiology. 1990;176(2):447-50.

22. Drevelegas A. Extra axial brain tumors. Eur Radiol. 2005; 15:453-67.

23. Nagar VA, Ye JR, Ng WH, Chan YH, Hui F, Lee CK, Lim CC. Diffusion-weighted MR imaging: diagnosing atypical or malignant meningiomas and detecting tumor dedifferentiation. AJNR Am J Neuroradiol. 2008;29(6):1147-52.

24. Surov A, Gottschling S, Mawrin C, et al. DiffusionWeighted Imaging in Meningioma: Prediction of Tumor Grade and Association with Histopathological Parameters. Translational Oncology. 2015;8(6):517-523.

25. Demir MK, Iplikcioglu AC, Dincer A, Arslan M, Sav A. Single voxel proton MR spectroscopy findings of typical and atypical intracranial meningiomas. Eur $J$ Radiol. 2006;60(1):48-55.

26. Buhl R, Nabavi A, Wolff S, Hugo HH, Alfke K, Jansen O, Mehdorn HM. MR spectroscopy in patients with intracranial meningiomas. Neurol Res. 2007;29(1):43-6.

27. Kousi E, Tsougos I, Fountas K, et al. Distinct peak at 3.8 ppm observed by 3T MR spectroscopy in meningiomas, while nearly absent in high-grade gliomas and cerebral metastases. Molecular Medicine Reports. 2012;5(4):1011-1018.

28. Jolapara M, Kesavadas C, Radhakrishnan VV, Thomas B, Gupta AK, Bodhey N, Patro S, Saini J, George $\mathrm{U}$, Sarma PS. Role of diffusion tensor imaging in differentiating subtypes of meningiomas. $J$ Neuroradiol. 2010;37(5):277-83.

29. Toh CH, Castillo M, Wong AM, Wei KC, Wong HF, Ng $\mathrm{SH}$, Wan YL. Differentiation between classic and atypical meningiomas with use of diffusion tensor imaging. AJNR Am J Neuroradiol. 2008;29(9):1630-5.

30. Valotassiou V, Leondi A, Angelidis G, Psimadas D, Georgoulias P. SPECT and PET imaging of 
meningiomas. Scientific World

Journal. 2012;2012:412580.

31. Lee JW, Kang KW, Park SH, Lee SM, Paeng JC, Chung JK, Lee MC, Lee DS. 18F-FDG PET in the assessment of tumor grade and prediction of tumor recurrence in intracranial meningioma. Eur J Nucl Med Mol Imaging. 2009;36(10):1574-82.

32. Ghodsian M, Obrzut SL, Hyde CC, Watts WJ, Schiepers C. Evaluation of metastatic meningioma with 2-deoxy2(18F) fluoro-D-glucose PET/CT. Clin Nucl Med. 2005;30:717-20.

33. Meirelles GS, Ravizzini G, Moreira AL, Akhurst T. Primary pulmonary meningioma manifesting as a solitary pulmonary nodule with a false-positive PET scan. $J$ Thorac Imaging. 2006;21:225-7.

34. Brennan C, O'Connor OJ, O'Regan KN, Keohane C, Dineen J, Hinchion J, Sweeney B, Maher MM Metastatic meningioma: positron emission tomography CT imaging findings. Br J Radiol. 2010;83(996):e25962.

35. Simpson D. The recurrence of intracranial meningiomas after surgical treatment. J Neurol Neurosurg Psychiatry. 1957;20:22-39.

36. Kondziolka D, Lunsford D, Coffey RJ, Flickinger JC: Stereotactic radiosurgery of meningiomas. J Neurosurg. 1991;74:552-559.

37. Ganz JC, Backlund EO, Thorsen FA. The results of Gamma Knife surgery for meningiomas, related to size of tumor and dose. Stereotact Funct Neurosurg. 1993;61(Suppl 1):23-29.

38. Hudgins WR, Barker JL, Schwartz DE, Nichols TD. Gamma Knife treatment of 100 consecutive meningiomas. Stereotact Funct Neurosurg. 1996;66 (Suppl 1):121-128.

39. Jhawar BS, Fuchs CS, Colditz GA, Stampfer MJ: Sex steroid hormone exposures and risk for meningioma. $J$ Neurosurg. 2003;99:848-853.
40. Longstreth WT Jr, Dennis LK, McGuire VM, Drangsholt MT, Koepsell TD: Epidemiology of intracranial meningioma. Cancer. 1993;72:639-648.

41. Muccioli G, Ghé C, Faccani G, Lanotte M, Forni M, Ciccarelli E: Prolactin receptors in human meningiomas: characterization and biological role. J Endocrinol. 1997;153:365-3731.

42. Grunberg SM, Weiss M: Lack of efficacy of megestrol acetate in the treatment of unresectable meningioma. $J$ Neurooncol. 1990;8:61-65.

43. Grunberg SM, Weiss MH, Spitz IM, Ahmadi J, Sadun A, Russell CA, et al: Treatment of unresectable meningiomas with the antiprogesterone agent mifepristone. J Neurosurg. 1991;74:861-866.

44. Goodwin JW, Crowley J, Eyre HJ, Stafford B, Jaeckle KA, Townsend JJ: A phase II evaluation of tamoxifen unresectable or refractory meningiomas: a Southwest Oncology Group Study. J Neurooncol. 1993;15:73-77.

45. Kaba SE, DeMonte F, Bruner JM, Kyritsis AP, Jaeckle KA, Levin V, et al: The treatment of recurrent unresectable and malignant meningiomas with interferon alpha-2B. Neurosurgery. 1997;40:271-275.

46. Schrell UMH, Rittig MG, Anders M, Koch UH, Marschalek R, Kiesewetter F, et al.: Hydroxyurea for the treatment of unresectable and recurrent meningiomas. II. Decrease in the size of meningiomas in patients treated with hydroxyurea. J Neurosurg. 1997;86:845-852.

47. Jensen RL, Origitano TC, Lee YS, Weber M, Wurster $\mathrm{RD}$. In vitro growth inhibition of growth factorstimulated meningioma cells by calcium channel antagonists. Neurosurgery. 1995;36:365-374.

48. Smith AB, Horkanyne-Szakaly I, Schroeder JW, Rushing EJ. From the radiologic pathology archives: mass lesions of the dura: beyond meningioma-radiologic-pathologic correlation. Radiographics. 2014;34(2):295-312. 